\title{
A AGRICULTURA URBANA EM ANANÁS/TO: SUBSÍDIOS PARA A SEGURANÇA ALIMENTAR E GERAÇÃ O DE RENDA ${ }^{1}$
}

\section{URBAN AGRICULTURE IN ANANÁS/TO: SUBSIDIES FOR FOOD SECURITY AND INCOME GENERATION}

\author{
Maria Marciene Costa DA SILVA ${ }^{2}$ \\ Maurício Ferreira MENDES ${ }^{3}$ \\ Luciano da Silva GUEDES ${ }^{4}$
}

\begin{abstract}
Resumo: A agricultura urbana assume papel estratégico no que tange a produção de alimentos, saúde e geração de renda. Neste contexto, o objetivo desta pesquisa foi diagnosticar a prática da horticultura no perímetro urbano de Ananás/TO, enfatizando a contribuição da produção de hortaliças no processo de promoção da segurança alimentar e nutricional para os moradores e consumidores locais, bem como o seu potencial gerador de renda. $\mathrm{O}$ delineamento utilizado foi a pesquisa exploratória, além de levantamentos de dados primários, por meio de entrevistas semiestruturadas, no período de abril a junho de 2019, além da coleta de dados secundários em órgãos oficiais. Constatou-se que a criação de políticas públicas a nível nacional e estadual contribuíram para a fixação de pessoas nas cidades, mas trouxe para o campo a concentração de terras, é neste contexto que o município de Ananás, Microrregião Geográfica do Bico do Papagaio, se insere. Assim, conclui-se que a prática da horticultura no perímetro urbano de Ananás é uma alternativa a uma alimentação saudável tanto para produtores, como para os consumidores, distribuindo renda e proporcionando um desenvolvimento para além do econômico, uma vez que perpassa pela questão social, alimentar e de saúde.
\end{abstract}

Palavras-Chaves: Horticultura; Saúde; Geração de renda; Bico do Papagaio.

\begin{abstract}
Urban agriculture assumes a strategic role in terms of food production, health and income generation. In this context, the objective of this research was to diagnose the practice of horticulture in the urban perimeter of Ananás/TO, emphasizing the contribution of vegetable production in the process of promoting food and nutritional security for residents and local consumers, as well as its generating potential income. The design used was exploratory research, in addition to the collection of primary data, through semi-structured interviews, from April to June 2019, in addition to the collection of secondary data in official agencies. It was found that the creation of public policies at national and state level contributed to the settlement of people in the cities, but brought to the countryside concentration of land, it is in this context that the municipality of Ananás, in the northern region of Tocantins. Thus, it is concluded that the practice of horticulture in the urban perimeter of Ananás is an alternative for healthy eating for producers and consumers, distributing income and providing a development beyond the economic one, since it goes through the social, food and health issue.
\end{abstract}

Keywords: Horticulture; Health; Income generation; Bico do Papagaio.

\footnotetext{
${ }^{1}$ Este artigo resulta do Trabalho de Conclusão de Curso intitulado “A prática da horticultura no perímetro urbano de Ananás (TO): subsídios para a segurança alimentar e geração de renda”, defendido em julho de 2019.

${ }^{2}$ Graduada em Geografia e mestranda no Programa de Pós-graduação em Demandas Populares e Dinâmicas Regionais (PPGDire) pela Universidade Federal do Tocantins (UFT). E-mail: marcienesilva.geo@gmail.com.

${ }^{3}$ Professor do curso de Geografia e do PPGDire/UFT. E-mail: mauricio.mendes@uft.edu.br.

${ }^{4}$ Professor do curso de Geografia e do PPGDire/UFT. E-mail: lucianoguedes@uft.edu.br.
} 


\section{Introdução}

A Agricultura Urbana (AU, doravante) manifesta-se na presença das práticas de horticulturas nas cidades, como a produção de hortaliças, plantas medicinais e árvores frutíferas. Apresenta grande relevância para os moradores locais, pois esta surge como uma possibilidade para a geração de renda, autoconsumo e saúde das famílias, ainda possibilita a perspectiva de desenvolvimento de projetos de educação ambiental no espaço urbano.

Essas práticas são realizadas em diversos espaços privados e públicos das cidades. É possível destacar algumas áreas com presença de hortaliças, sendo lotes vagos, terrenos baldios, lajes de casas, quintais residenciais, praças públicas, canteiros de avenida, escolas, creches, presídios, prédios públicos, entre outros. É o espaço onde as atividades rurais e urbanas se misturam (SANTANDREU; LOVO, 2007).

A prática da Agricultura Urbana nos bairros das cidades se traduz como uma forma de conservação da cultura dos horticultores, que são fortalecidas pelas relações com o quintal de casa, o bairro e as pessoas que compram as hortaliças, além da promoção da Segurança Alimentar e Nutricional (SAN, doravante). A SAN fomenta autonomia à comunidade ao permitir que as pessoas decidam quais hortaliças plantar, quais sementes escolher e que tipo de agricultura praticar (PIMBERT, 2009).

Diante do exposto, o objetivo deste artigo é discutir a prática da horticultura no perímetro urbano de Ananás/TO, enfatizando a contribuição da produção de hortaliças no processo de promoção da Segurança Alimentar e Nutricional, para os moradores e consumidores locais, bem como o seu potencial gerador de renda.

O delineamento utilizado para a realização desta pesquisa foi a exploratória que "tem como objetivo proporcionar maior familiaridade com o problema, com vistas a torná-lo mais explícito ou a construir hipóteses" (GERHARDT; SILVEIRA, 2009, p. 35). Realizou-se entrevistas estruturadas (questionários) e semiestruturadas por meio de perguntas abertas sobre a história da vida dos moradores de Ananás que têm a prática da horticultura; usou-se dados secundários do Instituto Brasileiro de Geografia e Estatística (IBGE) e Secretaria de Planejamento do Estado do Tocantins (SEPLAN/TO), além de revisão bibliográfica, trabalhos de campo e registro fotográfico.

As hortas do perímetro urbano de Ananás foram identificadas inicialmente por conhecimento do local por parte da pesquisadora e posteriormente utilizou-se a técnica metodológica snowball, que consiste na indicação dos próximos entrevistados a partir dos 
primeiros, ou seja, uma cadeia de informantes (BIERNACKI; WALDORF, 1981). Posteriormente, os dados foram digitados no programa Excel da Microsoft, no qual foram realizadas as estatísticas, possibilitando tecer as análises efetuadas neste texto.

O presente estudo foi estruturado em três partes, além desta introdução, considerações finais e referências. Na primeira parte apresentou-se as características histórico/geográficas do município de Ananás, na segunda discutiu-se a Segurança Alimentar e Nutricional e na terceira parte analisou-se a prática da horticultura em Ananás.

\section{Características histórico/geográficas e econômicas do município de Ananás}

O município de Ananás está localizado no Norte do estado do Tocantins (Figura 1) e faz parte da Microrregião Geográfica do Bico do Papagaio, situada na Mesorregião Ocidental, a sede do município fica a uma altitude de $218 \mathrm{~m}$, localizando-se no paralelo de $06^{\circ} 21^{\prime}$ '58" de latitude Sul e meridiano de 48 04' 24" de longitude Oeste (SEPLAN, 2017).

Figura 1 - Mapa de localização do município de Ananás (TO).

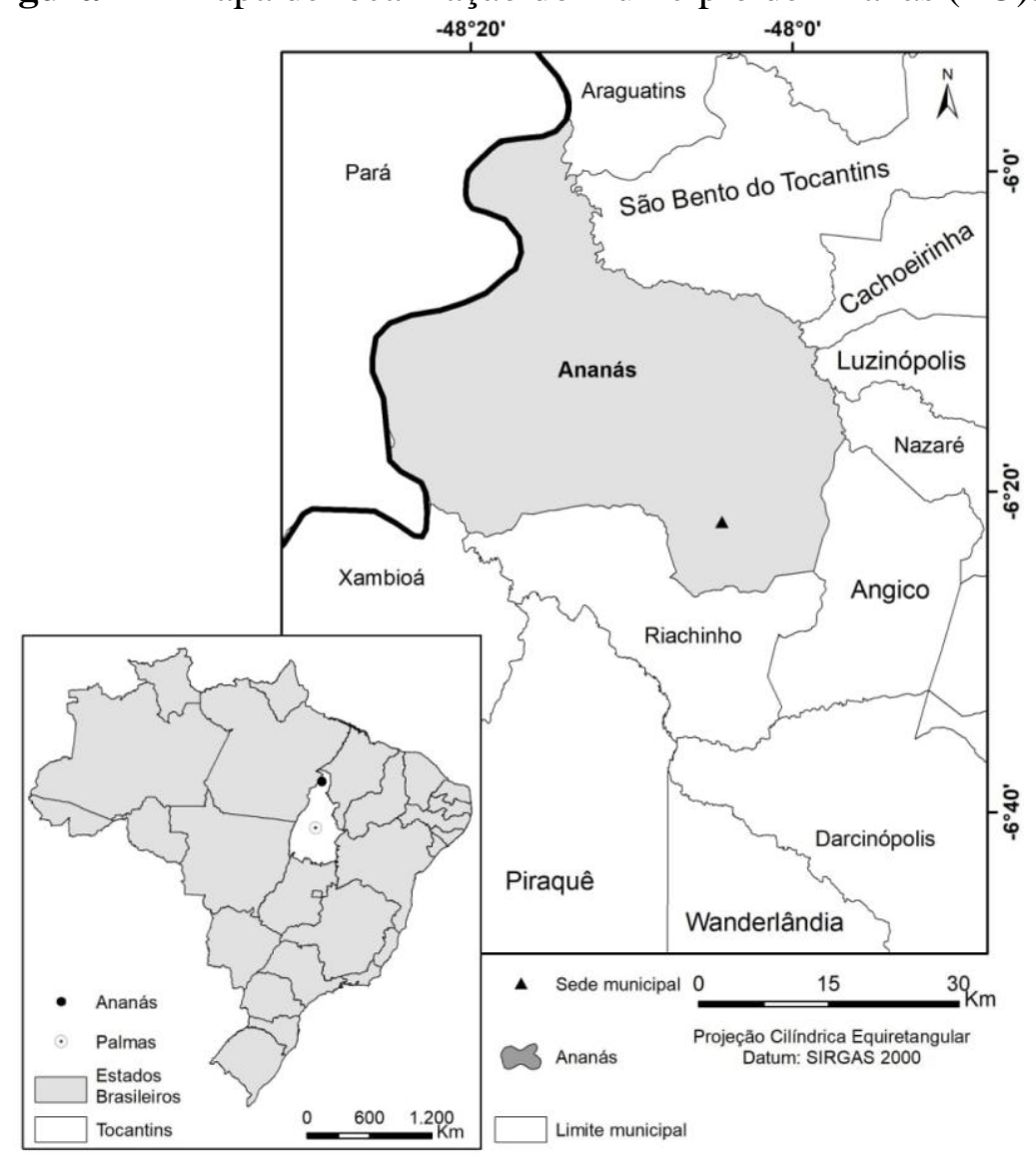

Fonte: Kreyton, J. P. Org: Os autores (2019). 
A área territorial do município de Ananás é de 1.576,973 km² limitando-se ao Norte com os seguintes municípios: Araguatins, São Bento do Tocantins, e o Estado do Pará; ao Sul com Riachinho e Xambioá; ao leste com Cachoeirinha, Luzinópolis, Nazaré e Angico; e a Oeste com o Estado do Pará (SEPLAN, 2017).

Ananás tem como marco as práticas rurais que são bastante evidenciadas na cultura desse lugar, visto que o processo de formação do município está diretamente ligado a pecuária, devido a implementação de políticas desenvolvimentistas ${ }^{5}$. Na área urbana, observase plantações de quiabo, mandioca e principalmente hortaliças nos quintais residenciais e em lotes vagos, demonstrando a diversidade da agricultura urbana. Nesse sentido, torna-se pertinente resgatar a questão histórica de Ananás para se pensar no atual contexto do município, em especial no que diz respeito às hortas urbanas.

Ananás tem sua formação atrelada à compra de terras. Oliveira (2014, p. 18) descreve o início da história de Ananás demonstrando que a aquisição de glebas de terras foi o principal fator que impulsionou o povoamento, primeiramente pelas famílias dos latifundiários e criadores de gado por volta dos anos de 1870.

Ananás, teve início segundo historiadores quando Teodoro Teófilo (ou George) Vanderlei, proveniente do Estado do Maranhão, possivelmente por volta de 1870, adquiriu por compra da paróquia de Filadélfia ou Boa Vista, uma gleba de terra que partia da cabeceira do ribeirão já conhecido por Morro Grande, passando pela cabeceira do ribeirão Lagoa, passando pelas margens do ribeirão Manga, ribeirão São Pedro, cabeceira do ribeirão Faca, alcançando a cabeceira do ribeirão Bacuri e por ele até sua embocadura no ribeirão Faca e por este, passando pela barra do ribeirão quati ou mutua no ribeirão Cruz e por este, até sua barra no ribeirão dos Porcos até a barra do ribeirão Pica-Pau seguindo em linha até alcançar o ribeirão Tapuia e ainda em linha até encontrar o ribeirão Morro Grande e por este até seu ponto de partida, atingindo assim, todas as campinas, ou seja, chapadas existente na região, que por ser muito fértil dedicou-se ao criatório de gado (OLIVEIRA, 2014, p. 18).

A partir de 1896, as terras passaram a ser vendidas para outras famílias, consequentemente, provocando a povoação da região. Este povoamento ocorre de fato até meados do século XX, quando a maior parte das famílias migraram do Nordeste, em especial do Maranhão e do Piauí e se estabeleceram nessas terras por causa da fertilidade do solo,

\footnotetext{
5 As décadas de 1960 e 1970 foram marcadas pela intervenção de políticas públicas desenvolvimentistas no Brasil. Essas políticas visavam transformar o rural e modernizá-lo, não considerando os impactos negativos. Conforme Grisa (2012, p. 18) no país foi se "inserindo uma estratégia mais ampla de desenvolvimento baseada na industrialização por substituição de importações, ou seja, o Estado assume de forma explícita o processo de capitalização do campo conjuntamente com o capital financeiro e industrial".
} 
extração dos benefícios da palmeira do babaçu, fruto nativo do Cerrado, e de áreas de transição amazônica e implantação roça de toco ${ }^{6}$.

O primeiro registro histórico foi a fixação da família José Honorato da Cruz, vinda do Maranhão por volta de 1903, onde hoje se ergue a sede principal [do município de Ananás]. Segundo os moradores mais antigos da localidade o senhor José Honorato, conhecido como Zé Pardim, adquiriu uma fazenda na localidade, denominando-a de Fazenda Ananás. O nome de Ananás foi escolhido devido esta ser uma planta nativa da região (com aparência e formato do abacaxi, porém maior e com mais cítrico), quando ali se iniciou a povoação. Anos mais tarde Zé Pardim vendeu para o senhor Firmino, que colocou alguns agregados dando início à povoação que foi acrescida com a chegada das famílias Lopes, Borges, Soares, Leão, Batista, Moura e Vieira. Em 1946, fixou residência nesse local o comerciante José Leite, com um comércio de compra de peles silvestres, amêndoas de babaçu e arroz, fornecendo em troca, tecidos, ferragens, calçados e munições. Naquela época, as principais atividades de subsistência da região eram o babaçu e a caça, onde se comia a carne e comercializavam o couro. [...] (ANANÁS, DECRETO LEGISLATIVO No 005/2016).

Destacamos que a agricultura familiar sempre esteve presente na formação do território ananaense, além de conflitos entre latifundiários e pequenos agricultores. Dois conflitos próximos levaram muitos migrantes para Ananás, o primeiro conflito foi entre Padre João e o fazendeiro Leão Ledra no lugar denominado "Boa Vista do padre João", atual município de Tocantinópolis/TO, e o segundo foi a Guerrilha do Araguaia ${ }^{7}$ (OLIVEIRA, 2014).

Em relação a formação político administrativa, o IBGE destaca que Ananás pertenceu a Boa Vista do Padre João, atual Tocantinópolis, mas no ano de 1958 passou a fazer parte de Nazaré/TO. Ananás também foi distrito do município de Araguatins até 1963, ano que oficialmente foi instalado o município de Ananás, por meio da Lei Estadual n. ${ }^{\circ} 4.684$, de 14 de outubro de 1963.

Fazendo um salto temporal, o último censo demográfico realizado pelo IBGE indicou que Ananás apresentou 9.865 habitantes em 2010 (Tabela 1), sendo que 82,55\% da população reside na área urbana (SEPLAN, 2017). Partes desses moradores estabelecem vínculos com a

\footnotetext{
${ }^{6}$ A roça de toco ou coivara consiste numa tradição bastante antiga de corte das principais árvores arbóreas e posterior queima para iniciar o plantio, muito utilizada pelos povos; comunidades tradicionais e indígenas do Norte do Tocantins.

7 A Guerrilha do Araguaia (1972-1974) acontece nos estados Pará, Maranhão e Norte de Goiás (atual estado do Tocantins). Surgiu em decorrência de enfrentamento à ditadura terrorista, como alternativa de enfrentamento ao estado de exceção inaugurado em 31 de março de 1964. Nesse período, todos os canais de respiração política do país estavam amordaçados, os camponeses não podiam reivindicar, a imprensa se encontrava censurada e os livros apreendidos (PORTAL VERMELHO, 2020).
} 
zona rural, uma vez que esta cidade é cercada por terras propícias à culturas de ciclos curtos e também muitos oriundos da zona rural.

Tabela 1 - Evolução populacional de Ananás (1991- 2018).

\begin{tabular}{cc}
\hline Ano & População \\
\hline 1991 & 11.851 \\
2000 & 10.512 \\
2010 & 9.865 \\
2018 (Estimativa população) & 9.607 \\
\hline
\end{tabular}

Fonte: IBGE/Censos Demográficos 1991/2000/2010. Org: autores (2019).

Conforme a tabela 1, entre os anos de 1991 e 2018 houve uma desaceleração do crescimento populacional. A principal explicação para a diminuição da população residente, segundo os moradores, se dá pela migração dos jovens para continuar os estudos e buscar melhores oportunidades de trabalho e renda, uma vez que a pecuária, principal atividade na região, gera poucos postos de trabalho e concentra a renda em número restrito de famílias (LOPES, 2018). Essa tendência de redução populacional concentra-se principalmente nos municípios brasileiros com até 20.000 habitantes (IBGE, 2017).

A respeito da criação de gado em Ananás, Lopes (2018) apresenta análises sobre o trabalho dos ananaenses, afirmando que essa cidade tem sua base na economia primária, com alta concentração de terras e poucas oportunidades para a população, decorrente das políticas adotadas.

[...] Ananás é uma cidade em cujo redor se encontram as grandes fazendas, seja no seu município, seja em outras regiões de fronteira, como o Pará. De certa maneira, os fazendeiros utilizam a mão de obra do trabalhador que vive em sua periferia. Este município possui um ambiente rural com características patronais, em que o dono da terra utiliza a mão de obra contratada, apresentando às vezes o assistencialismo, como moradia, alimentação, transporte etc. [...] (LOPES, 2018, p. 205).

Devido à pouca oportunidade de empregos, necessidade de cursos superiores e serviços médicos em Ananás, 18,94\% da população migraram para outras localidades, como as cidades de Araguaína, Palmas e Goiânia, tornando-se cidades que absorvem parte da população de Ananás, considerando os anos de 1991 a 2018 (Tabela 1) (LOPES, 2018).

Contudo, se muitas famílias acabaram migrando para outras cidades, outras estão buscando adaptar-se às oportunidades existentes em Ananás. Portanto, as famílias que permanecem na cidade acabam criando alternativas para melhorar a qualidade de vida, como por exemplo a produção e comercialização de hortaliças no perímetro urbano da cidade, como será discutido mais adiante. 


\section{Segurança Alimentar e Nutricional e Agricultura Urbana}

A Agricultura Urbana e a Segurança Alimentar e Nutricional vêm sendo estudadas como alternativas aos problemas que a população vem enfrentando, sobretudo no que diz respeito à fome, mas é necessário frisar que os benefícios da AU perpassam esta questão e contribui também para um ambiente mais propício a manutenção de áreas verdes, diminuindo as ilhas de calor nas cidades e melhorando a qualidade de vida, tanto em relação a alimentação, como no cuidado como o ambiente.

Coutinho (2010) argumenta que a Agricultura Urbana está inteiramente ligada à Segurança Alimentar e Nutricional e que os debates norteadores dessa temática surgem a partir da década de 1940, ganhando força em 1946, com a publicação do livro "Geografia da Fome”, do brasileiro Josué Castro. Castro questionou a concentração de capital e de terras, associando o regime da fome ao latifúndio e a estrutura agrária altamente concentrada no país, defendendo e afirmando a necessidade urgente da reforma agrária no Brasil.

O surgimento do conceito de Segurança Alimentar e Nutricional também perpassa pelo contexto final da Segunda Guerra Mundial, com o aparecimento das consequências pósguerra, nesse período ficou nítido que a vida da população mundial estava ameaçada pela escassez de alimentos, sendo estabelecido um indicador social de SAN, com a criação da Organização das Nações Unidas para a Agricultura e Alimentação - FAO/ONU (MARDEGAN, 2014).

A FAO/ONU foi criada em 1945 e funciona como um fórum onde os países tanto desenvolvidos como os emergentes discutem políticas direcionadas a SAN. Este fórum atende tanto às áreas rurais como urbanas, contribuindo para a melhoria das atividades agrícolas de forma sustentável no mundo

No Brasil, as políticas públicas de SAN são discutidas a nível nacional no âmbito do Conselho Nacional de Segurança Alimentar (Consea), que é um espaço de debates e proposição de políticas para o setor. A nível estadual, as políticas são discutidas no âmbito dos Consea's estaduais, mas nem todos os estados têm os conselhos estruturados e em pleno funcionamento. Essas políticas [de SAN] são importantes, pois de acordo com a FAO (2018, p. 08) a Insegurança Alimentar e Nutricional (IAN) aumentou entre os anos de 2014 e 2017 em quase todo o mundo, com exceção da América Setentrional e Europa (Gráfico 1). 
Gráfico 1 - Panorama da (In)segurança Alimentar e Nutricional no mundo (2014-2017).

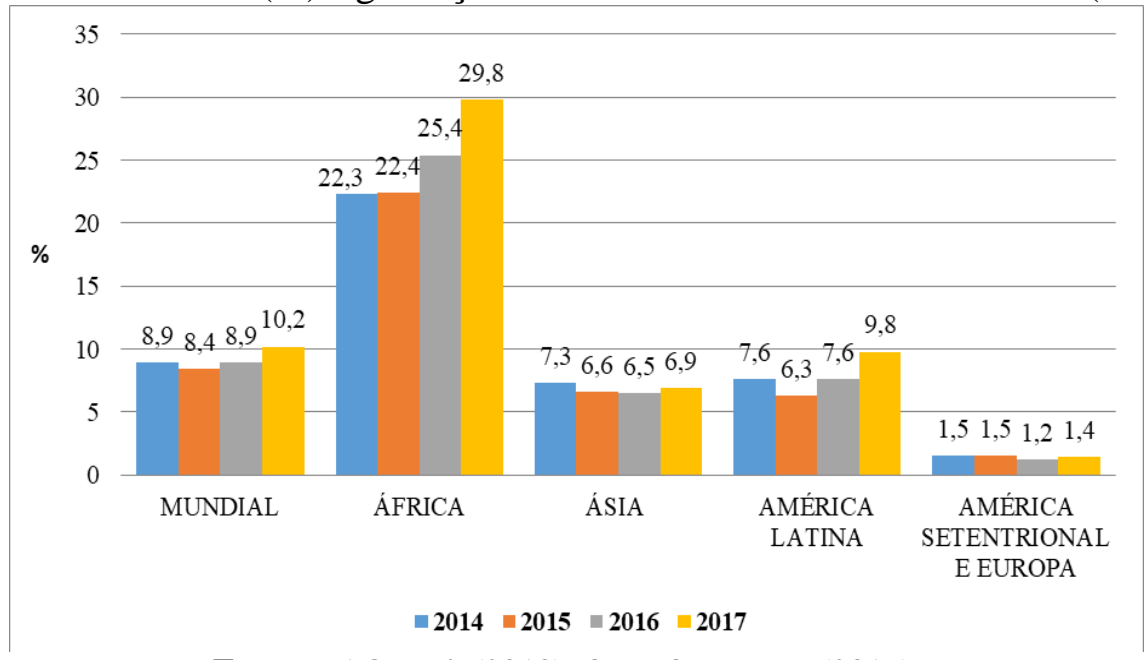

Fonte: FAO et al. (2018). Org.: Os autores (2019).

O panorama mundial aponta que houve um aumento da IAN da população, principalmente na África, Ásia e América Latina. Merece preocupação o continente africano que entre as demais regiões é o que apresenta maior porcentagem de IAN. Chegando a quase 30\% da população em 2017 (Gráfico 1), principalmente em função das heranças do colonialismo e a opção por um modelo econômico voltado quase que exclusivamente para a produção de commodities destinada ao mercado externo.

Esses dados também demonstram que no ano 2017 cerca de 10,2\% da população mundial, o que equivale a quase 800 milhões de pessoas estavam em situação de insegurança alimentar e até mesmo em desnutrição. Na América Latina em 2014, a IAN correspondia a $7,6 \%$ tendo diminuído para $6,3 \%$ em 2015 , porém o panorama mais recente traz um aumento desse percentual para 9,8\%. Segundo a FAO/ONU (2018), as mulheres, os jovens e os negros são os mais afetados pela insegurança alimentar.

No Brasil, as políticas públicas visando melhorar esse quadro, enfocam ações voltadas para o combate à fome, ao fortalecimento da agricultura familiar, dos quais se destacam os programas: Fome Zero, Programa Nacional de Fortalecimento da Agricultura Familiar (PRONAF), Programa de Organização Produtiva de Comunidades (PRODUZIR), Plano Nacional de Desenvolvimento da Pesca e Aquicultura, Programa Nacional de Alimentação Escolar (PNAE), Programa de Aquisição de Alimentos (PAA), além do trabalho de entidades como a Confederação Nacional dos Trabalhadores na Agricultura (CONTAG), Federações de Trabalhadores na Agricultura Familiar (FETAGS), ONG's e universidades que contribuem por meio de ensino, extensão e pesquisas (NAÇÕES UNIDAS BRASIL, 2019). 
Porém, estas políticas públicas estão sendo desmanteladas pelo atual governo, colocando em risco a promoção da SAN e anos de investimentos em políticas de combate à fome, ciclo iniciado em 2003. É preciso voltar a reconhecer a importância da agricultura familiar como fator primordial que alimenta a população brasileira e dos movimentos sociais na defesa de direitos para a classe trabalhadora.

Além disso, o estado brasileiro tem o dever de assegurar o direito à alimentação [conforme previsto na Constituição Federal], principalmente para a população mais carente. Nesse sentido umas das ações mais expressivas sobre a SAN no país foi a criação do Sistema Nacional de Segurança Alimentar e Nutricional (SISAN), que passou a vigorar a partir da Lei $\mathrm{n}^{\mathrm{o}}$. 11.346, de 15 de setembro de 2006 .

O SISAN tem como objetivo colocar em prática ações governamentais junto à população para possibilitar e promover alternativas ao IAN, garantindo a cada pessoa uma alimentação de qualidade. A Lei 11.346/2006 estabelece em seu artigo $3^{\circ}$, a definição de SAN:

A segurança alimentar e nutricional [SAN] consiste na realização do direito de todos ao acesso regular e permanente a alimentos de qualidade, em quantidade suficiente, sem comprometer o acesso a outras necessidades essenciais, tendo como base práticas alimentares promotoras de saúde que respeitem a diversidade cultural e que sejam ambiental, cultural, econômica e socialmente sustentáveis (BRASIL, 2006, p. 1).

É indiscutível que os debates a respeito da alimentação e da fome perpassam pela questão do modelo de desenvolvimento, acesso à educação e a implementação de políticas públicas. Mardegan (2014) explica que não é suficiente que a população tenha alimento, além disso, estes devem ser de qualidade, pois a segurança alimentar representa o acesso e também diz respeito à saúde.

Essa relação entre acesso a alimentos e qualidade de vida torna-se necessário para pensar nos caminhos que a SAN está percorrendo em Ananás e no Tocantins, uma vez que o Estado do Tocantins junto com o Maranhão, Piauí e Bahia fazem parte da fronteira agrícola conhecida por Matopiba ${ }^{8}$. Essa fronteira agrícola foca na produção de commodities para a exportação. Somente no Tocantins, a expansão das áreas de agricultura capitalista aumenta $25 \%$ todo ano, de acordo com a Companhia Nacional de Abastecimento (CONAB).

\footnotetext{
${ }^{8}$ O Matopiba foi oficialmente criado pelo Decreto presidencial $n^{\circ}$. 8.447, de 6 de maio de 2015. Para mais informações, consulte: https://www.embrapa.br/tema-matopiba.
} 
É importante destacar que para a produção nessas áreas é necessária grande quantidade de agrotóxicos e pesticidas, além do desmatamento das fitofisionomias do Cerrado. Esses fatores prejudicam o solo, que é o principal meio de produção de alimentos, a água, a fauna e a saúde dos moradores próximos a essas áreas. "Em 2018, foram desmatadas mais florestas no Tocantins do que em qualquer outro estado do bioma Cerrado. O Tocantins é um estado predominantemente rural. [...]. Em 2018, o desmatamento no Tocantins foi de 153.320 ha, ou 23\% do total desmatado no Cerrado" (DROST et al, 2019, p. 1).

Dados da Pesquisa Nacional por Amostra de Domicílios sobre SAN realizada pelo IBGE, em 2013, mostra que as regiões Norte e Nordeste possuem o maior índice de IAN. Apesar disso, o Tocantins apresentou uma diminuição da IAN, em 2009, que correspondia a 16,8\%; e em 2013 passou para 10,1\%, porém, mesmo com esse balanço positivo não se deve anular a necessidade de pensar essa questão de forma mais ampla e no bojo das atuais mudanças no Estado.

\section{A prática da horticultura como expressão da agricultura urbana em Ananás}

A produção de hortaliças nas áreas urbanas é uma atividade econômica que adquire grande expressividade em função dos seus benefícios, pois possibilita o fornecimento de alimentos com custos mais acessíveis à população, contribui para a renda das famílias que cultivam hortaliças nos quintais de sua residência e em lotes vagos, como acontece no perímetro urbano de Ananás, além de melhorar e diversificar a alimentação dos moradores.

\footnotetext{
Agricultura Urbana é um conceito multidimensional que inclui a produção, o agroextrativismo e a coleta, a transformação e a prestação de serviços, de forma segura, para gerar produtos agrícolas (hortaliças, frutas, ervas medicinais, plantas ornamentais, etc.), pesca e pecuários (animais de pequeno, médio e grande porte) voltados ao auto - consumo, trocas e doações ou comercialização, (re) aproveitando-se, de forma eficiente e sustentável, os recursos e insumos locais (solo, água, resíduos sólidos, mão de obra, saberes etc.) (ASPTA, 2015, p. 1).
}

É importante ressaltar que a AU também apresenta pontos negativos, a partir do momento que essa prática envolve o uso de produtos prejudiciais ao solo, a água e de modo geral, ao ecossistema urbano, em função dos elementos químicos e artificiais presentes em pesticidas e agrotóxicos. 
No âmbito da AU, a prática da horticultura merece atenção, pois trata-se de uma atividade que com o passar do tempo passou por vários aperfeiçoamentos técnicos. Se antes as técnicas empregadas eram mais elementares, hoje pode envolver a ciência e novas tecnologias.

No desenvolvimento da pesquisa, constatou-se que Ananás apresenta diversas práticas de horticultura, com destaque para a cultura de alface, couve, cebolinha, quiabo, maxixe, entre outros. Os produtores de hortaliças primeiramente consomem as hortaliças e posteriormente comercializam o excedente na própria cidade. Ademais, ocorre a troca de sementes e mudas de hortaliças e o cultivo envolve técnicas manuais de produção oriundas de herança familiar. Essas práticas de agricultura "desafiam modelos hegemônicos de ocupação das cidades, contrastando com os padrões de planejamento e gestão do território", portanto, "a estrutura e a dinâmica afeta diretamente as formas de fazer agricultura urbana (ASPTA, 2015, p. 2).

Por meio do contato com os moradores, na cidade em tela foram identificadas 12 (doze) hortas urbanas, todas em quintais residenciais e lotes vagos, sendo duas hortas em cada localidade, a seguir: rua Getúlio Vargas, bairro Chapadinha I; ruas Barão do Rio Branco, 9 de julho e Quintino Bocaiuva, todas no centro. As demais estão localizadas na rua São Pedro, rua Antônio Moreira, rua Paraíso, e avenida Betel, sendo uma de cada localidade e todas na região central de Ananás. As entrevistas foram realizadas com os proprietários das hortas elencadas.

Os entrevistados possuem entre 30 e 60 anos de idade e declararam ter suas origens em diversos estados brasileiros. Destes, $40 \%$ são do Tocantins, $40 \%$ são naturais da região Nordeste, principalmente dos estados do Maranhão e Ceará, e 20\% são oriundos da região Sudeste, do estado de Minas Gerais. Antes de migrarem para a área urbana de Ananás, todos os horticultores entrevistados residiam em áreas rurais dos seus respectivos municípios de origem. Durante a pesquisa foi averiguado que atualmente os entrevistados não pensam em mudar para outros estados e/ou regiões, pois em Ananás estabeleceram vínculos afetivos com as pessoas e com a produção.

As famílias são formadas, em média, por quatro pessoas, sendo que uma família possui um número de nove membros e a outra tem seis. Destaca-se que $40 \%$ das famílias vivem exclusivamente da renda proveniente da comercialização das hortaliças, demonstrado que a Agricultura Urbana pode gerar oportunidades de trabalho e renda. É importante destacar que a renda para essas famílias vai além da questão quantitativa e financeira, pois adquire 
significações em função dos conhecimentos culturais que envolvem todo o processo de produção das hortaliças.

Destaca-se também que $40 \%$ dos horticultores contam com o auxílio dos filhos no trabalho de cultivo e comercialização das hortaliças, além do trabalho externo [dos filhos], diversificando a renda familiar, o que ajuda principalmente em períodos de chuva, onde é mais difícil e caro produzir hortaliças. O trabalho familiar é questão central para a superação da pobreza, com o cooperativismo, geração de renda, diversificação da produção e acesso a mercados (SIDERSKY; JALFIM; RUFINO, 2008).

Dentre as famílias, $60 \%$ são representadas pelas mulheres que trabalham na própria residência, cuidam dos filhos e estão à frente do processo de produção das hortaliças, além de investimentos na produção de sabão e na prática de costura. Segundo Pimbert (2009) esses sistemas alimentares locais proporcionam a base para a nutrição, renda, economias e cultura das famílias.

Todas as experiências aqui apresentadas têm como tema mobilizador a Segurança Alimentar e Nutricional, com destaque para as mulheres que estão na frente do processo e enfrentando contextos muitas vezes desfavoráveis, como a vulnerabilidade social e econômica (PACHECO, 2009). A seguir, apresentamos algumas experiências exitosas de horticultoras e horticultores de Ananás.

A primeira horticultora reside em Ananás há 30 anos, antes morava em Sororoca, pequeno povoado integrante do município de Riachinho/TO. A entrevistada aprendeu a trabalhar com hortas a partir de incentivos e cursos realizados por meio do Centro de Direitos Humanos de Araguaína/TO (CDH-TO), há mais de 11 anos, disponibilizando mudas, equipamentos e em alguns casos até terrenos vazios para moradores cultivarem hortaliças.

Arrendaram um terreno do senhor Antonio Rio Grandense, três linha de terra pra fazer essa horta, aí então essa horta só podia entrar pessoas que não tinha terra, pessoas que não tinham condição de sobreviver de outra forma, aí eles forneceram a semente, fornecia as instrução, tinha as pessoa que davam as instruções, fazia as reuniões aqui na minha casa, muitas vezes era aqui outras vezes era lá na horta, enquanto não tinha local reunia aqui, reunia na casa de outra pessoa que também estava cadastrado (Entrevista concedida à autora em Junho/2019).

A horticultora ressalta que foi a partir dessa iniciativa do CDH-TO que passou a se interessar pela prática de produzir alface, couve, pimentão, cebolinha, maxixe, coentro, cebolinha, alface, rúcula, pimenta de cheiro, quiabo e jiló, vindo a inclusive fazer novos cursos de aperfeiçoamento, melhorando assim, a qualidade e a quantidade da produção. 
A comercialização acontece no próprio local da horta, porém enfatiza-se que é necessário um aporte do poder público para comercialização destes produtos. Sobre este tema, Porto (2008) comenta que no Brasil o tema comercialização via agricultura familiar e cinturões verdes tem ganhado projeção, principalmente com o espaço de fóruns, como o Consea e fóruns de desenvolvimento local, conselhos de alimentação das escolas, entre outros. Porém, é necessário uma participação mais direta do Estado nas compras públicas de pequenas iniciativas, como a produção de hortaliças em Ananás. Alguns estabelecimentos comerciais preferem comprar o produto de fora, ao invés de famílias locais.

A horta localiza-se no quintal de sua própria residência (Figura 2), e ocupa uma área de $504 \mathrm{~m}^{2}$. A proximidade de uma represa junto a horta, facilita a irrigação (Figura 3) e consequentemente aumenta a produção.

Figura 2 - Horta na Avenida Betel.

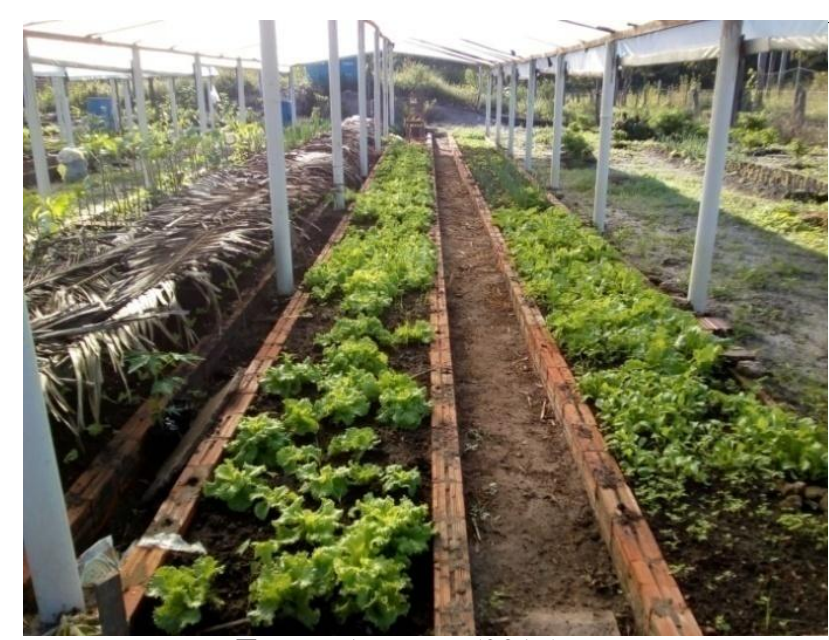

Fonte: A autora (2019).
Figura 3 - Represa construída pelos proprietários da horta.

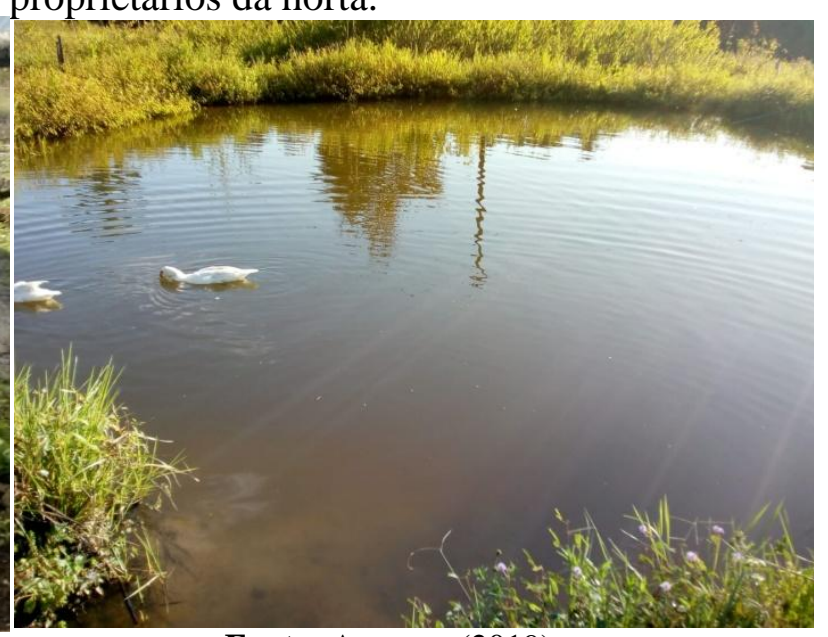

Fonte: A autora (2019).

Na mesma horta utiliza-se uma tela para sombreamento com o objetivo de proteger as hortaliças da chuva e do calor excessivo, além do sombrite, também utilizam palha de babaçu sobre o canteiro, isso ocorre por dois motivos, o primeiro diz respeito a abundância da planta na região; o segundo é que o babaçu ajuda a diminuir o calor sobre as mudas recém transplantadas, evitando que murchem e sequem. "Uma vantagem dos espaços pequenos é que geralmente é mais fácil cobrir a área de cultivo com telas redutoras de luz conhecida como sombrite e controlar a temperatura e a umidade, mantendo um clima mais adequado as plantas o ano todo" (INSTITUTO PÓLIS, 2020, p. 12).

A preparação do solo para o cultivo envolve o uso de adubos como o esterco de gado que é abundante na região, por causa da concentração de fazendas destinadas à pecuária, além 
de cama de frango e compostagem de matéria orgânica, sendo esta a opção de adubo mais utilizada no período chuvoso. Os alimentos cultivados na horta são consumidos pela família e comercializados na feira local.

Outra horticultura pesquisada é de propriedade de uma residente em Ananás desde 1981, natural do estado do Maranhão, onde morava na zona rural. Segundo relato da mesma, a prática da horticultura sempre esteve presente na sua vida e era a forma como seus pais conseguiam alimentar a família. A entrevistada afirma que todos os seus conhecimentos de hortaliças são resultados da aprendizagem familiar, e que esse foi o motivo que a levou a plantar; durante sua infância via a mãe cultivando o alho, a cebola, o coentro, a cebolinha, entre outros. Atualmente, os canteiros dessa horticultora ocupam mais de $98 \mathrm{~m}^{2}$.

As hortaliças produzidas nessa horta residencial são alface, couve, rúcula, salsa, pepino, cebolinha, coentro e pimenta de cheiro, que são comercializadas na própria residência, na feira e nas ruas da cidade pela filha da horticultura, conferindo a família a renda mensal de até $\mathrm{R} \$ 700,00$ (setecentos reais). As figuras 4 e 5 são um recorte de um dos canteiros dessa horta.

Figura 4 - Horta na Rua 9 de Julho.

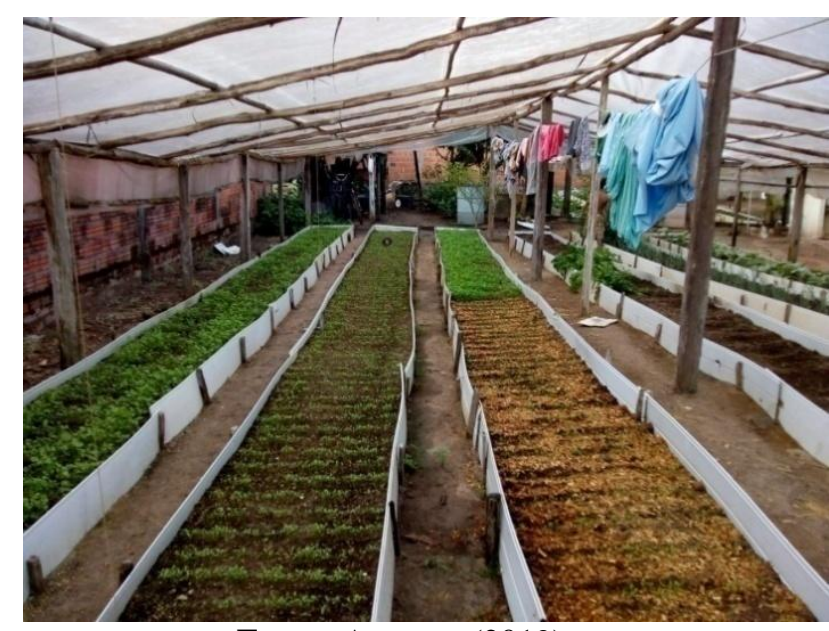

Fonte: A autora (2019).
Figura 5 - Canteiro de couve.

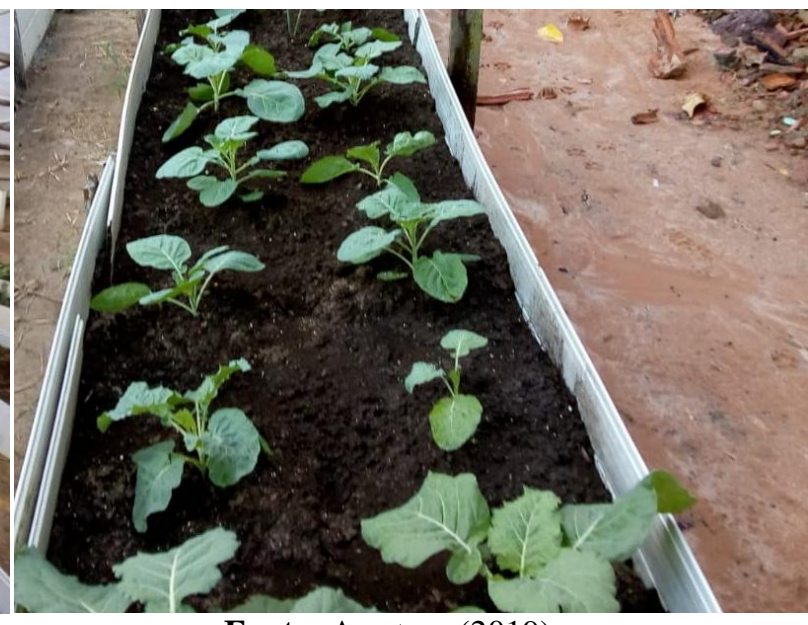

Fonte: A autora (2019).

Nessa horta, a horticultora utiliza pó de serragem; além do esterco de gado, sendo que o controle de pragas é realizado a partir do uso de inseticida natural fabricado a partir da planta chamada Nim (Azadirachta indica).

Os canteiros são cobertos por sombrite e sustentados por armação de madeira, no interior da horta utilizam-se CDs (Compact disc) que refletem feixes de luzes coloridas, segundo a horticultora essa foi a forma barata encontrada e que realmente funciona para espantar os passarinhos, uma vez que as aves comem as sementes semeadas. 
A entrevistada destaca que não há nenhum tipo de crédito ou programa público voltado para a produção de hortaliças em Ananás, dificultando a produção e a comercialização. Ela enfatiza que todos os equipamentos, sementes, insumos foram adquiridos com recursos próprios e, também que muitos aprendizados e experiências são compartilhadas junto aos demais horticultores da cidade.

Porto (2008) afirma que é necessário vontade política do Estado para que as compras públicas alcancem a classe trabalhadora e não somente os grandes mercados capitalistas. É preciso que o arcabouço institucional se ajuste às iniciativas como a produção de hortaliças em Ananás.

A próxima horta a ser apresentada, também tem uma mulher como protagonista. Tratase de uma horticultora que residia na zona rural de Minas Gerais, mas mudou-se para de Ananás em 1970. Esta por sua vez manteve suas práticas agrícolas, aprendizados e identidade mediante o cultivo de hortaliças e criação de pequenos animais em casa, como galinhas. Assim, como constatado nas hortas residenciais descritas anteriormente, a horticultora não recebe nenhum auxílio e/ou apoio do poder público. Porém, conta com a contribuição do marido na produção.

As hortaliças produzidas nessa horta são consumidas pela família e comercializadas no município, como feiras livres, mercados e no próprio local, proporcionando uma renda mensal de R\$ 500,00 (Quinhentos reais) a essa família por mês. Valor esse não suficiente para manutenção da casa, sendo necessário, além da horticultura, investir na produção de sabão artesanal e cultivar ervas medicinais para a produção de xaropes (Figuras 6 e 7).

Figura 6 - Horta na Rua Getúlio Vargas

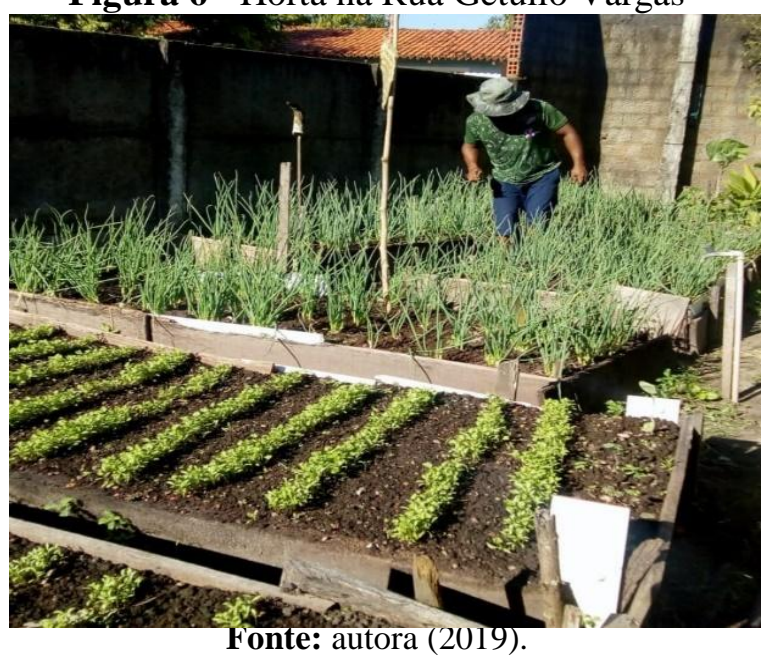

Figura 7 - Ervas plantadas em baldes

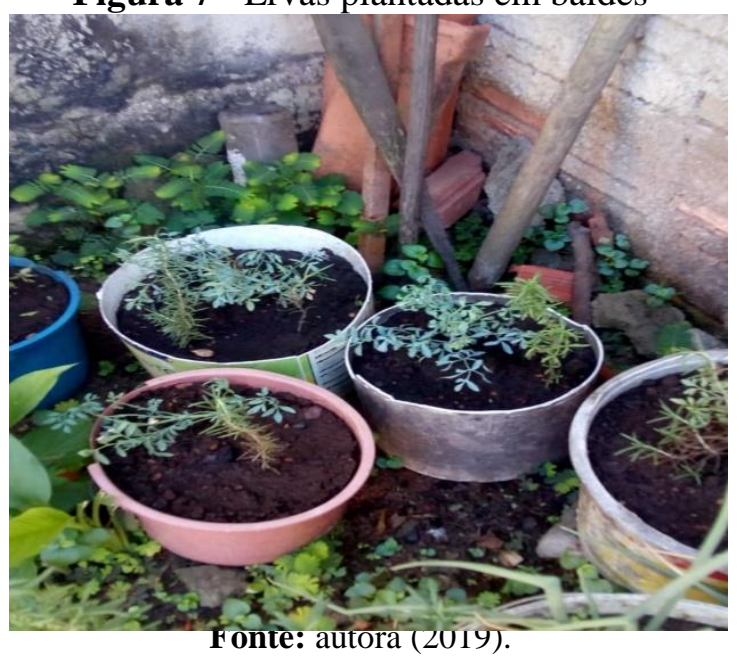


Nessa horta é utilizado o "chifre de gado" no meio dos canteiros, que segundo a horticultora serve para que as cebolinhas cresçam bonitas e saudáveis e também para o afastamento de "mau olhado". A irrigação das hortaliças e ervas cultivadas pela horticultura é realizada com a água de poço, além da água encanada. Bizari e Cardoso (2016) enfatizam a necessidade de repensar os modelos atuais de uso de água, uma vez que o recurso natural está cada vez mais escasso, principalmente para a população em vulnerabilidade socioeconômica.

O próximo horticultor de destaque é natural da cidade de Quixeramobim, estado do Ceará. Reside em Ananás há mais de 40 anos, atualmente a sua horta possui em torno de 800 $\mathrm{m}^{2}$, está localizada em dois lotes ao lado do quintal da sua residência. Destaca-se que esse horticultor tem formação em curso superior na área de biologia, além de curso técnico agrícola. As figuras 8 e 9 mostram parte da horta, além de uma doença acometida na cultura da alface

Figura 8 - Produção de hortaliças na Rua Antonio Moreira.

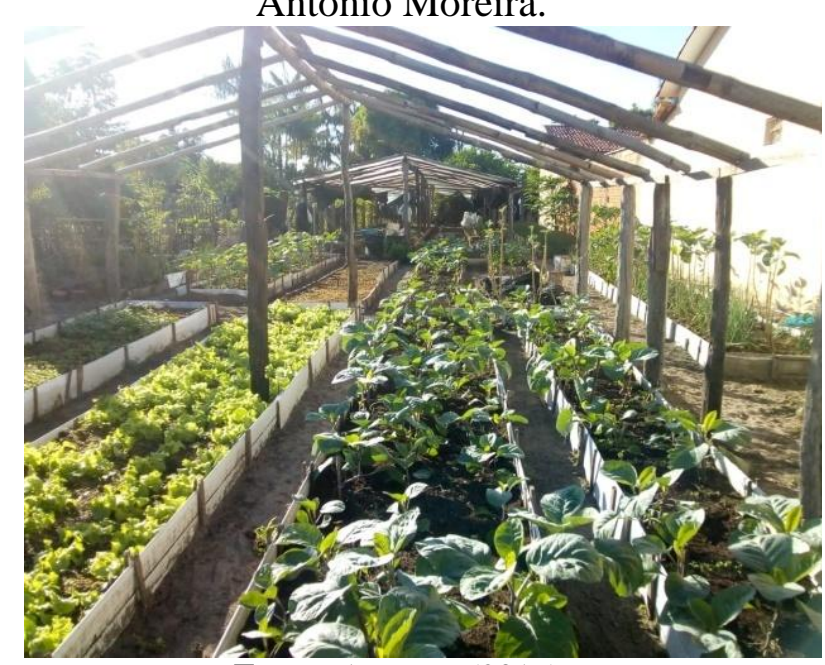

Fonte: A autora (2019).
Figura 9 - Doença na cultura do alface.

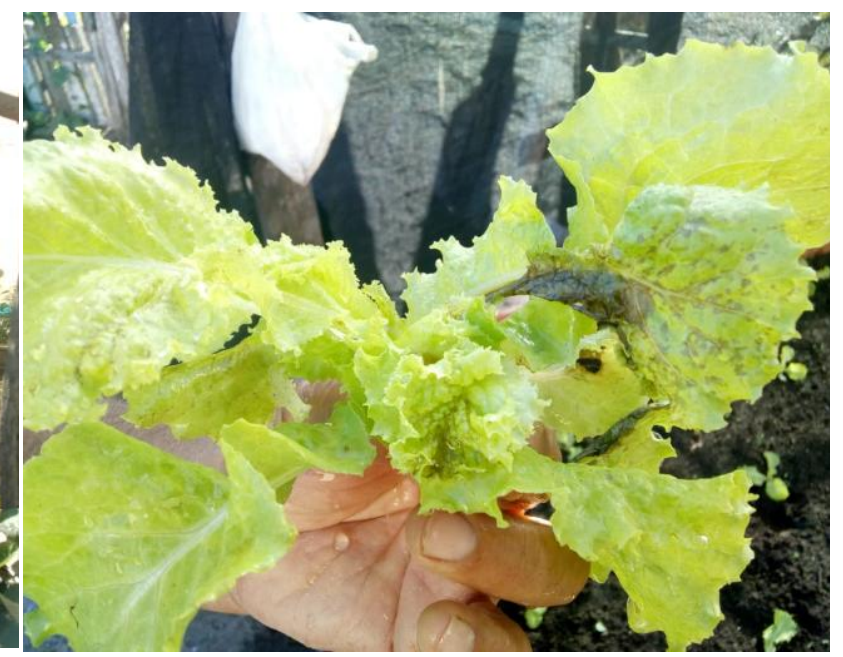

Fonte: A autora (2019).

As culturas cultivadas nessa horta são: alface, rúcula, salsa, coentro, cebolinha, couve, maxixe, pepino, fava e inhame. O pepino e o maxixe são cultivados distante das hortaliças folhosas, pois segundo o entrevistado esses dois vegetais podem trazer pragas para as demais hortaliças. A respeito de pragas, o horticultor relata que:

Trato as pragas só com produtos naturais [...], ás vezes uso [...] vinagre com alho, um pouquinho de pimenta do reino, um pouquinho de álcool, faço a calda e boto, por exemplo, meio litro de álcool, meio litro de vinagre, um pouquinho de pimenta do reino, uns quatro a cinco dentes de alho aí eu faço a calda, em um litro de calda mais ou menos eu coloco em 20 litros de água. Aí jogo nas plantas só para controlar, ela não mata mais controla para não botar veneno [...] (Entrevista concedida à autora em Junho/2019). 
Destaca-se que a Agricultura Urbana aproxima campo e cidade, além de contribuir para estruturação de circuitos próximos de produção e consumo (ASPTA, 2015). O horticultor descreve que comercializa hortaliças e fornece principalmente alfaces para lanchonetes da cidade, destacando que já apresentou prejuízos por causa de doenças nas plantas, em especial da alface e da couve. De acordo com o entrevistado surgiram manchas necróticas no tecido vegetal dessas hortaliças, conforme apresentado na figura 9, ocasionando a perda de toda a sua produção. O horticultor também possui plantas frutíferas, como o cupuaçu e o caju.

A quinta entrevista foi realizada em uma horta situada em um lote vago na cidade, essa horta apresenta melhor estrutura em relação às outras visitadas. Antes de trabalhar com hortaliças, esse horticultor desenvolvia atividades em empresas e foi a partir dos recursos financeiros recebidos após a sua demissão que este empregou na construção da horta, hoje com mais de $700 \mathrm{~m}^{2}$ (Figuras 10 e 11).

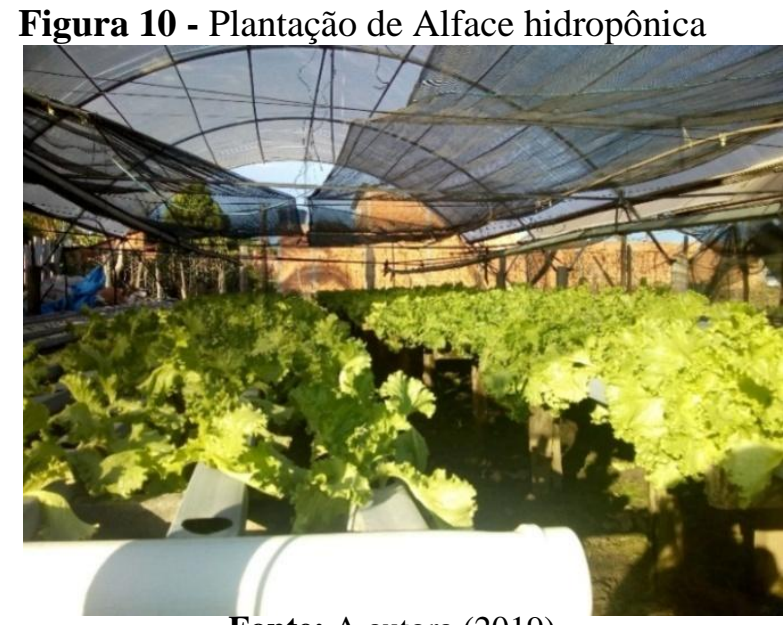

Fonte: A autora (2019).

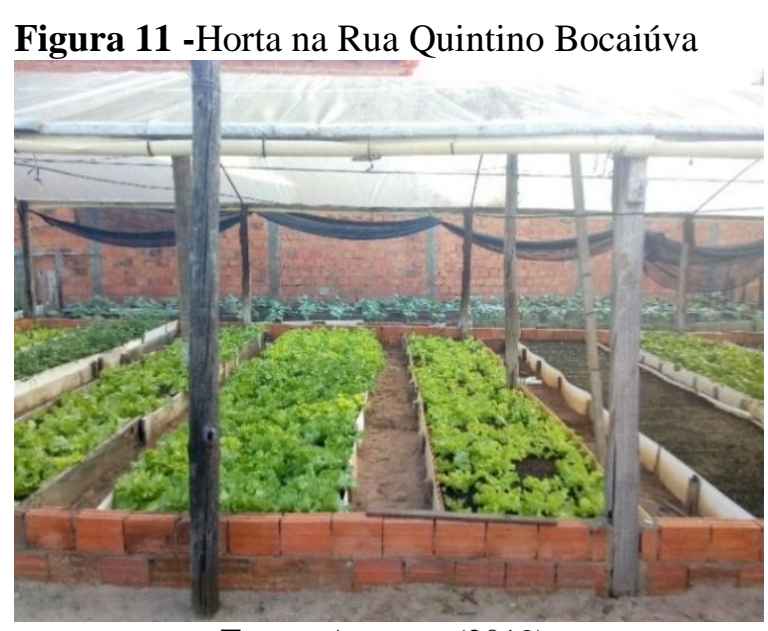

Fonte: A autora (2019).

Nessa horta a produção de alface ocorre por meio de dois processos, via hidroponia, onde o cultivo ocorre em suspensão passando água junto com nutrientes constantemente absorvidos pelas raízes da alface e também por meio de canteiros, no qual as hortaliças são plantadas no solo. De acordo com o entrevistado, a hidroponia funciona a partir do bombeamento de água acrescidos de nutrientes colocados manualmente em uma caixa de água, essa água é proveniente de um poço. Podemos afirmar que a hortas do perímetro urbano de Ananás utilizam princípios sustentáveis de produção, o que corrobora com a ASPTA (2015, p. 4) "é possível afirmar que grande parte das práticas de agricultura urbana [do Brasil] costuma adotar princípios da agroecologia, especialmente a adubação orgânica, o controle de pragas e doenças, o policultivo [...]”. 
Há um sistema de irrigação formado por uma bomba que direciona água a plantação hidropônica de 15 em 15 minutos, ainda foi observada irrigação de canteiros por meio de regador manual, fita de gotejamento e mangueira.

A produção de mudas é feita a partir da plantação de sementes que são adquiridas nos comércios destinados à agropecuária em Ananás e em Araguaína (TO). Essas sementes são colocadas em sementeiras onde são adicionados substratos fornecedores de macro e micronutrientes necessários para o desenvolvimento das hortaliças.

Todavia, a agricultura urbana permanece com invisibilidade, muitas pessoas, comunidades, associações de bairros praticam a agricultura urbana, porém ela não aparece nos planos diretores dos municípios, não existem políticas públicas de apoio a essas experiências (ASPTA, 2015).

\section{Considerações finais}

Em Ananás destaca-se cultivos direcionados a alimentação da população, tendo como carro chefe da produção, as hortaliças, além do cultivo de ervas medicinais e plantação de árvores frutíferas nos quintais residenciais, direcionada ao autoconsumo familiar e posteriormente a comercialização. A prática da horticultura nos quintais em Ananás também é importante não só para o ambiente, mas também para a qualidade de vida dos moradores.

A representatividade dos quintais como espaços de produção reforça a cultura e identificação das famílias ananaenses, contribuindo para a saúde e diversificação do ambiente. Essas práticas também expressam a história das pessoas que atribuíram ao lugar e a um conjunto de possibilidades de acordo com as suas experiências.

Constatamos também que as políticas públicas para o incentivo à produção de hortaliças em Ananás são mínimas e/ou inexistentes, é necessário que o poder público municipal reconheça a importância dessa prática, colocando em debate as discussões sobre a segurança alimentar e desenvolvendo ações direcionadas a horticultura na cidade, bem como oferecer incentivos para a prática da Agricultura Urbana, que é uma forma de aproveitar os espaços, contribuindo para a limpeza da cidade e também disponibilizando aos horticultores cursos de aperfeiçoamento.

Por fim, é importante destacar que o desenvolvimento de hortas urbanas não somente geram renda, mas também contribuem para a inclusão social de famílias em vulnerabilidade 
EM

QUESTÃO

econômica, além de incidir diretamente na promoção da Segurança Alimentar e Nutricional de Ananás.

\section{Referências}

AGÊNCIA IBGE. Quase 25\% dos municípios tiveram redução de população em 2017. Disponível em: https://agenciadenoticias.ibge.gov.br/agencia-noticias/2012-agencia-denoticias/noticias/16132-quase-25-dos-municipios-tiveram-reducao-de-populacao-em-2017.

Acesso em: jan. 2021.

ANANÁS. Decreto legislativo No 005/2016. História do município Antiga e Moderna de Ananás. Disponível em: https://ananas.to.gov.br/municipio/historia. Acesso em: 22 maio. 2019.

ASPTA. Subsídio para uma Política Nacional de Agricultura Urbana Periurbana (PNAUP). Disponível em: https://aueufmg.files.wordpress.com/2016/07/subsidio-pol-nacagric-urb-periurb.pdf. Acesso em: jun. 2019.

BRASIL. Lei ${ }^{\circ} 11.346,15$ de setembro de 2006. Cria o Sistema Nacional de Segurança Alimentar e Nutricional (SISAN), com vistas em assegurar o direito humano à alimentação adequada e dá outras providências. Disponível em: http://www.planalto.gov.br/ccivil_03/_ato2004-2006/2006/lei/111346.htm. Acesso em: maio. 2019.

BIERNACKI, P.; WALDORF, D. Snowball Sampling: Problems and techniques of Chain Referral Sampling. Sociological Methods \& Research, vol. nº 2, p. 141-163, 1981.

BIZARI, Douglas R.; CARDOSO, JEAN C. Água de reuso e horticultura urbana: aliança para criação de cidades mais sustentáveis. Hortic. Bras. v. 34, n.3, p. 311-317, 2016.

COUTINHO, Maura Neves. Agricultura urbana: práticas populares e sua inserção em políticas públicas. 2010. 204 f. Dissertação (Programa de Pós-Graduação em Geografia) Instituto de Geociências da Universidade Federal de Minas Gerais, UFMG, Belo Horizonte/MG, 2010.

DROST, S.; KUEPPER, A. B.; PIOTROWSKI, P. M; ADVISERS, C. Tocantins: um hotspot para o desmatamento do cerrado. 2019. Disponível em: https://chainreactionresearch.com/wp-content/uploads/2019/04/CRR_Tocantins-ReportPortuguese.pdf. Acesso em: abr. 2019.

FAO/ONU - Organização das Nações Unidas para a Alimentação e a Agricultura. El estado de la seguridad alimentaria y la nutrición en el mundo. Disponível em: http://www.fao.org/3/I9553ES/i9553es.pdf. Acesso em: abr. 2019.

GERHARDT, Tatiana Engel; SILVEIRA Denise Tolfo. Métodos de pesquisa. Porto Alegre: Editora da UFRGS, 2009. 
EM

QUESTÃO

V.14 N. $01 \bullet 2021$

pág. 77-97

GRISA, Cátia. Políticas públicas para a agricultura familiar no Brasil: produção e institucionalização das ideias. 2012. 280 f. Tese (Doutorado em Ciências Sociais) - Instituto de Ciências Humanas e Sociais, Universidade Federal Rural do Rio de Janeiro, Seropédica/RJ, 2012.

IBGE. Instituto Brasileiro de Geografia e Estatística. Censo demográfico. Disponível em: https://www.ibge.gov.br/estatisticas/sociais/populacao/. Acesso em: maio. 2019.

INSTITUO PÓLIS. Hortas urbanas: moradia urbana com tecnologia social. Disponível em: https://polis.org.br/wp-content/uploads/Hortas-Urbanas-FINAL-bx-site.pdf. Acesso em: ab. 2020.

LOPES, Alberto Pereira. Escravidão por dívida no Tocantins-Brasil: vidas dilaceradas. Curitiba: Appris, 2018.

MARDEGAN, Gláucia Elisa. Segurança alimentar, sua origem e as medidas de prevenção do Brasil e Argentina. Disponível em: http://www.cbg2014.agb.org.br/resources/anais/1/1404153327_ARQUIVO_Glaucia_mardega n.pdf. Acesso maio. 2019.

NAÇÕES UNIDAS BRASIL. Organização das Nações Unidas para a Alimentação e a Agricultura - FAO, 2019. Disponível em: https://nacoesunidas.org/agencia/fao/. Acesso abr. 2019.

OLIVEIRA, Sara Costa de. Processo de Formação do Município de Ananás-TO. 2014. 32f. Monografia - Programa Nacional de Formação de Professores da Educação Básica (PARFOR), Universidade Federal do Tocantins, Araguaína, 2014.

PACHECO, Maria Emília Lisboa. Os caminhos das mudanças na construção da Agroecologia pelas mulheres. Revista Agriculturas, Rio de Janeiro, v. 6, n. 4, p. 4-8, 2009.

PIMBERT, Michel. Mulheres e soberania alimentar. Revista Agriculturas, Rio de Janeiro, v. 6, n. 4, p. 41-46, 2009.

PORTAL VERMELHO. O PC do B e a guerrilha do Araguaia: a estratégia. Disponível em: $\quad$ https://vermelho.org.br/2012/04/06/o-pcdob-e-a-guerrilha-no-araguaia-a-estrategia/. Acesso em: abr. 2020.

PORTO, Silvio Isopo. Acesso a mercados: desafios e oportunidades. Revista Agriculturas, Rio de Janeiro, v. 5, n. 2, p. 4-6, 2008.

SANTANDREU, Alain; LOVO, Ivana Cristina. Panorama da agricultura urbana e periurbana no Brasil e diretrizes políticas para sua promoção: identificação e caracterização de iniciativas de AUP em regiões metropolitanas brasileiras. Documento Referencial Geral: Belo Horizonte: 2007.

SEPLAN. Secretaria de Planejamento do Estado do Tocantins (SEPLAN/TO). Diretoria de Pesquisas e Informações Econômicas. Perfil socioeconômico dos municípios: Ananás. 2017. Disponível em: https://central3.to.gov.br/arquivo/348471/. Acesso em: ago. 2019. 
SIDERSKY, Pablo; JALFIM, Felipe; RUFINO, Expedito. Combate a pobreza rural e sustentabilidade no semiárido nordestino: a experiência do projeto Dom Helder Camara. Revista Agriculturas, Rio de Janeiro, v. 5, n. 4, p. 23-28, 2008.

Artigo recebido em 13-04-2020 Artigo aceito para publicação em 17-02-2021 